\title{
A Biosensor-Based Assay (GInLux-Agar) Shows Defoliation Triggers Rapid Release of Glutamine from Nodules and Young Roots of Forage Legumes
}

\author{
Malinda S. Thilakarathna and Manish N. Raizada ${ }^{\dagger}$ \\ Department of Plant Agriculture, University of Guelph, 50 Stone Road, Guelph, ON, Canada N1G 2W1 \\ Accepted for publication 8 April 2019.
}

\section{ABSTRACT}

Forage legumes experience defoliation from grazing and injury in both natural and agricultural ecosystems. Defoliation induces rhizodeposition of nitrogen $(\mathrm{N})$ compounds from root systems that can feed microbes and plants that depend on the rhizosphere. The literature suggests that $\mathrm{N}$ exudates are primarily released from root tips, and those from legume nodules are released via slow nodule decomposition. However, the early timing and precise locations of $\mathrm{N}$ release postdefoliation are poorly characterized. The objectives of this study were to directly image tissuespecific $\mathrm{N}$ exudation sites in forage legumes, specifically for glutamine, and to do so at early time points postdefoliation. Glutamine is the primary assimilate of symbiotic nitrogen fixation in nodules and a key transport form of fixed $\mathrm{N}$ in amideexporting legumes. Three amide-exporting forages, alfalfa (Medicago sativa), red clover (Trifolium pretense), and white clover (Trifolium repens), were defoliated or not, and placed on agar embedded with whole cell biosensor cells ( $G \operatorname{lnLux}$ ) that detect glutamine. There were two unexpected findings. First, Gln release occurred rapidly, starting within $2 \mathrm{~h}$ postdefoliation, depleting rapidly. Second, the sources of early GIn release were primarily nodules in addition to the expected young lateral roots/ root tips. Lux quantification statistically confirmed the key findings. These observations suggest that $\mathrm{N}$ exudate release should be added to the list of defoliation stress early responses in nodules, and may have implications for our understanding of how defoliation impacts the rhizosphere microbiome.

Furthermore, GInLux-agar imaging represents a new assay to explore the proposed but yet unknown mechanisms underlying organic $\mathrm{N}$ exudation in plants.

Keywords: biosensor, defoliation, ecology, glutamine, legume, nitrogen, nodule, plants, root exudate, symbiosis
Legumes fix atmospheric $\mathrm{N}_{2}$ into usable nitrogen $\left(\mathrm{NH}_{3} / \mathrm{NH}_{4}{ }^{+}\right)$ through symbiotic bacteria inhabiting root nodules, a process termed symbiotic nitrogen fixation (SNF) (Udvardi and Poole

\section{Corresponding author: M. N. Raizada; raizada@uoguelph.ca}

Author contributions: M.S.T. conceived of the manuscript, designed the study, and conducted all experiments. M.S.T. wrote the manuscript. M.N.R. edited the manuscript and supervised the study. All authors discussed the results and commented on the manuscript. All authors read and approved the final manuscript.

The authors declare that the research was conducted in the absence of any commercial or financial relationships that could be construed as a potential conflict of interest. However, the GlnLux technology has a U.S. patent pending.

Funding: This research was supported by CIFSRF from the International Development Research Centre, Ottawa (grant 107791) and Global Affairs Canada.

*The $e$-Xtra logo stands for "electronic extra" and indicates that three supplementary figures and one supplementary material file are published online.

(C) 2019 The American Phytopathological Society
2013). Due to subsequent depositions of SNF-derived N fertilizer into soil, legumes can reduce the synthetic $\mathrm{N}$ fertilizer requirements of companion intercrops/mixed crops and rotation crops (e.g., cereals) (Thilakarathna et al. 2015, 2016a, b). Nitrogen is transferred belowground from legumes to neighbors through three major pathways: (i) decomposition/mineralization of $\mathrm{N}$ compounds from legume root systems; (ii) legume root exudation of $\mathrm{N}$ compounds; and (iii) $\mathrm{N}$ transfer mediated by plant-associated mycorrhizae (Thilakarathna et al. 2016a).

Defoliated legumes (associated with herbivory, harvesting) show enhanced N transfer to neighboring nonlegumes (Ayres et al. 2007; Saj et al. 2008; Tarui et al. 2013). Defoliation removes the primary sink for root-derived $\mathrm{N}$ (e.g., leaf RuBisCo) and primes the exudation of $\mathrm{N}$ compounds from legume root systems, though studies are limited (Ayres et al. 2007; Carrillo et al. 2011; Hamilton et al. 2008; Høgh-Jensen and Schjoerring 1994; Ofosu-Budu et al. 1995a, b). $\mathrm{N}$ compound exudation has been observed days-to-weeks postdefoliation, with the earliest recorded release being one day postdefoliation in alfalfa (Brophy and Heichel 1989; Ta et al. 1986). 
Compared with slow decomposition-mediated release, the latter report of rapid release of $\mathrm{N}$ is surprising, given that it is more prone to leaching and may not benefit alfalfa which is perennial and needs bioavailable $\mathrm{N}$ for regrowth (Corre et al. 1996). To the best of our knowledge, no studies have confirmed the above result in other legumes, nor tested $\mathrm{N}$ release at earlier time-points (hours) postdefoliation. In general, assessments of $\mathrm{N}$ rhizodeposition are challenging (Fustec et al. 2010; Oburger and Jones 2018). Root tips and nodules are proposed to be major sites of legume $\mathrm{N}$ release, but no clear data exists concerning the exact sites and mechanisms of $\mathrm{N}$ exudation (Lesuffleur and Cliquet 2010). The precise timing and cell/tissue-specific site(s) of postdefoliation $\mathrm{N}$ release remain unknown.

Inside nodules, rhizobia-derived fixed $\mathrm{N}$ is assimilated into the amino acid glutamine (Gln) (Tegeder 2014) which is also a key export form of fixed $\mathrm{N}$ in amide-exporting legumes (including alfalfa and clover) (Unkovich et al. 2008). We previously developed an imaging assay for Gln using a whole-cell biosensor called GlnLux (Goron and Raizada 2016; Tessaro et al. 2012). GlnLux was created by transforming an Escherichia coli Gln auxotroph with a constitutive lux reporter (Tessaro et al. 2012). Freeze-thawed nodules were shown to release Gln onto agar containing GlnLux cells (GlnLux agar), allowing them to multiply and release photons detectable by a photon capture camera as lux images (Thilakarathna and Raizada 2018). The assay employs white and false-colored lux images, wherein blue-green represent the lowest lux intensity (low Gln concentration) and red-orange the highest (high Gln concentration) (Thilakarathna and Raizada 2018). A lux halo around a plant tissue can represent an intensive source of Gln and/or time for diffusion, which can be distinguished by a time course, with the signal dissipating once Gln is consumed by GlnLux cells (Goron and Raizada 2016; Thilakarathna and Raizada 2018). SNF-output inferred from the GlnLux assay strongly correlated with $\mathrm{N}$ derived from SNF (Thilakarathna et al. 2017).

Here, using the GlnLux-agar assay, for the first time, Gln release was directly imaged from legume root systems (non-freeze-thawed) following defoliation. Root systems of defoliated and nondefoliated forage legumes (alfalfa, red, and white clover) were compared, mimicking natural herbivory and harvesting of livestock fodder.

\section{MATERIALS AND METHODS}

Detailed methods are available in Supplemental Material S1.

Biological materials. The crops and respective rhizobia were alfalfa cultivar OAC-Minto with Sinorhizobium meliloti Rm1021 (Kassaw et al. 2015); and red clover cultivar Tempus and white clover cultivar Sacramento, both with Rhizobium leguminosarum biovar trifolii Mj43 (Janczarek et al. 2009).

Plant growth conditions. Surface-sterilized seeds were germinated in growth pouches as described (Thilakarathna and Raizada 2018), supplied with $1 / 4$ strength $\mathrm{N}$-free Hoagland's solution ( $\mathrm{pH}$ 6.8), and then inoculated with compatible rhizobia.

GlnLux-agar preparation. GlnLux biosensor cells (Tessaro et al. 2012) were embedded in agar to create $G \ln L u x$-agar plates for lux imaging using a ChemiProHT imager (Roper, U.S.A.) as described (Thilakarathna and Raizada 2018).

GlnLux imaging. Healthy, green plants with numerous nodules were selected 4 to 5 weeks postinoculation. To defoliate, shoots were removed just above the cotyledons. Stems were inserted in grooves created on the sides of the agar plates; roots were then pressed down (Fig. 1), plates inverted, incubated at $30^{\circ} \mathrm{C}$ and imaged hourly ( 1 to $12 \mathrm{~h}$ ) with $1,000 \mathrm{~s}$ exposure times. Six plates/ crop were imaged from two independent trials.
Image quantification. A 50-by-50-pixel area was selected around every visible nodule for lux quantification. Nodules close to plate edges were avoided as they had poor contact with GlnLuxagar. A 50-by-50-pixel area absent of root organs (average of $n=3$ ) was used to subtract background lux.

Statistics. For statistical analysis, a total of six GlnLux plates, three from two completely independent trials, were used per treatment, grown at separate times and imaged at different times on independent GlnLux plates. The $n$ values (number of nodules/ nodule clusters measured for lux) are noted in each figure legend. The total lux intensity per nodule and mean intensity per pixel from GlnLux images were compared for defoliated versus undefoliated plants using Mann-Whitney tests $(P<0.05)$ with Prism (v7, GraphPad Software, U.S.A.).

\section{RESULTS}

The strategy to visualize Gln release from nodulated root systems consisted of their placement onto agar containing GlnLux cells (GlnLux-agar) (Fig. 1A). Based on visual observations, dramatically more photons were emitted from GlnLux-agar exposed to root systems from defoliated plants compared with intact plants in all three legumes: alfalfa (Fig. 1B to J, Supplementary Fig. S1), red clover (Fig. 2A to I, Supplementary Fig. S2), and white clover (Fig. 2J to R, Supplementary Fig. S3) based on direct photon capture (Fig. 1C, E, and G; Fig. 2B, D, and F; Fig. 2K, M, and O) or false color conversion (Fig. 1D, F, and H; Fig. 2C, E, and G; Fig. 2L, N, and $\mathrm{P}$, with blue-green being the lowest intensity, red-orange the highest, and a halo reflecting diffused Gln). Lux quantification confirmed the visual observations statistically: defoliation triggered significantly higher total lux intensity per nodule (Fig. 1I; Fig. 2H and Q) and mean intensity per pixel (Fig. 1J; Fig. 2I and R) compared with nondefoliated controls. Visually, the most noticeable photon emission increases postdefoliation were associated with nodules.

Photon emission from GlnLux-agar was observed from root systems rapidly, within $2 \mathrm{~h}$ postdefoliation in alfalfa (Fig. 1C and D), red clover (Fig. 2B and C), and white clover (Fig. 2K and L). Maximum photon emission (broad halo with red-orange color) occurred $6 \mathrm{~h}$ postdefoliation in alfalfa (Fig. 1E and F), red clover (Fig. 3D and E), and white clover (Fig. 2M and N). Interestingly, photon emissions diminished by $12 \mathrm{~h}$ postdefoliation (narrow halo with green color) in alfalfa (Fig. $1 \mathrm{G}$ and $\mathrm{H}$ ), red clover (Fig. $2 \mathrm{~F}$ and $\mathrm{G})$, and white clover (Fig. $2 \mathrm{O}$ and P).

Photon emissions were also associated with young lateral roots and root tips from defoliated plants, especially in red clover (Figs. $2 \mathrm{~B}$ to $\mathrm{G}$ ) and white clover (Fig. $2 \mathrm{~K}$ to $\mathrm{P}$ ).

\section{DISCUSSION}

In agricultural and natural ecosystems, defoliation is associated with grazing, mowing, and damage from herbicides, insects and/or frost. Most studies have focused on defoliation-mediated root carbon release and its influence on rhizosphere activity (Ayres et al. 2004; Bazot et al. 2005; Holland et al. 1996; Murray et al. 2004). However, defoliation was also shown to alter soil dynamics via $\mathrm{N}$ rhizodeposition (Ayres et al. 2004, 2007; Carrillo et al. 2011). Here, for the first time, the effect of defoliation on organic $\mathrm{N}$ release (Gln) was directly visualized. There were two novel findings: first, defoliation stimulated organic $\mathrm{N}(\mathrm{Gln})$ release within hours rather than days/weeks as previously shown (Brophy and Heichel 1989; Ta et al. 1986); second, nodules were a direct source of this early $\mathrm{N}$ exudate, whereas the literature has focused on root tips (Badri and Vivanco 2009; Coskun et al. 2017; Lesuffleur and Cliquet 2010; 

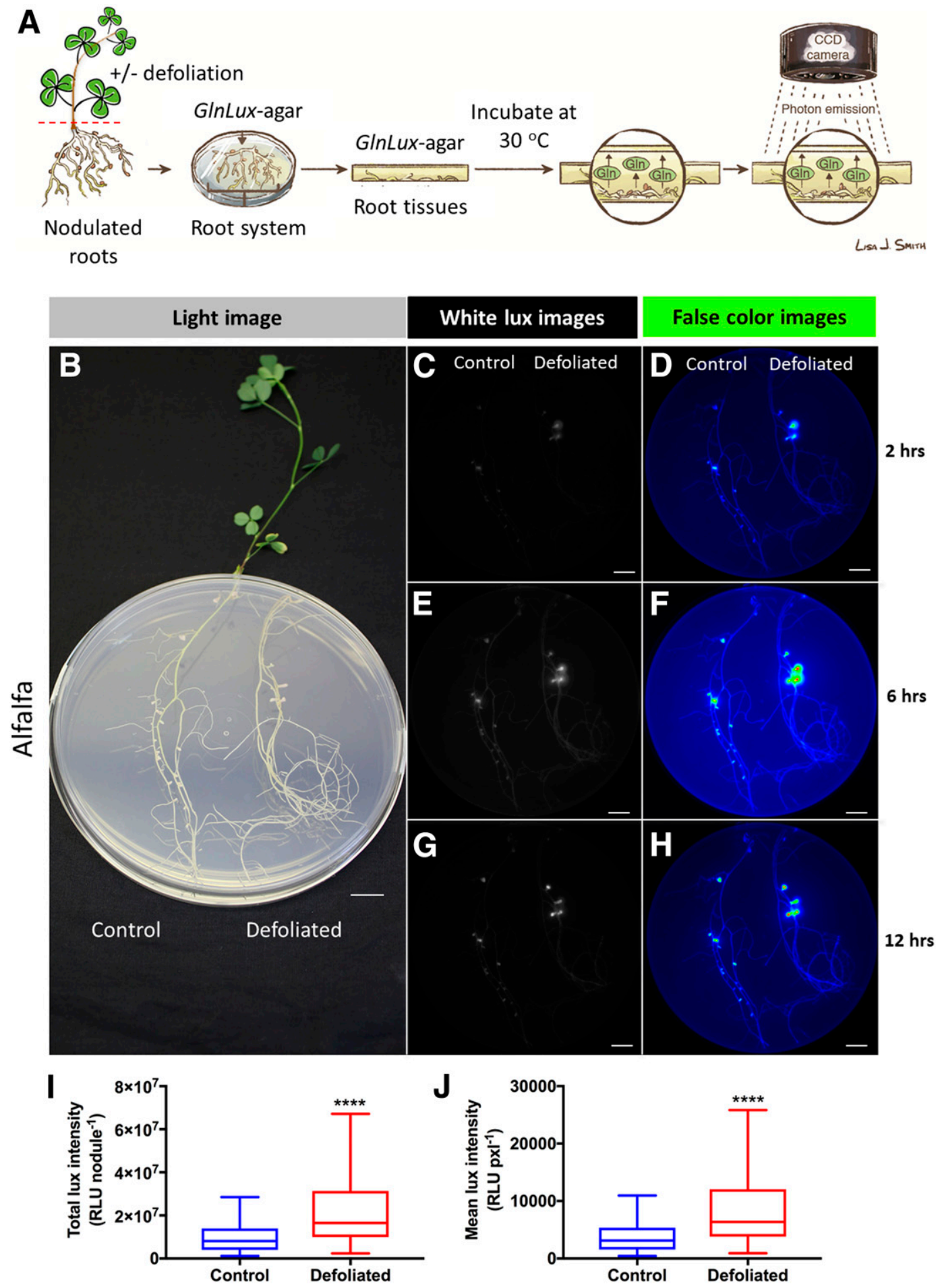

Fig. 1. Imaging and quantification of GIn release from nodulated root systems of alfalfa following defoliation or nondefoliated controls, using the GInLuxagar biosensor assay. A, GInLux-agar method overview: legume root systems are pressed down on agar pre-embedded with GInLux reporter cells, referred to as GInLux-agar. When Gln is released from root tissues to the medium, it is taken up by GInLux biosensor cells, causing them to become metabolically active and divide, which proportionally activates a lux operon to release photons that are detected using a photon capture (CCD) camera. Plates are inverted, then incubated at $30^{\circ} \mathrm{C}$ to allow for the released plant Gln to activate adjacent biosensor cells and imaged hourly ( 0 to $12 \mathrm{~h}$ ). $\mathbf{B}$ to $\mathbf{H}$, Imaging of nodulated root systems of defoliated and nondefoliated alfalfa plants using the GlnLux-agar assay. B, Light image of a root system of a representative 6-week-old alfalfa plant that was defoliated (right) and a noninjured control (left) placed on a GInLux-agar plate. C, E, and $\mathbf{G}$, White lux images and $\mathbf{D}, \mathbf{F}$, and $\mathbf{H}$, false-colored lux images after 2, 6, and $12 \mathrm{~h}$ of incubation immediately after defoliation. Bright green-yellow-red color areas with halos represent plant tissues showing the greatest Gln release including nodules. I to J, Corresponding quantitative analysis of luminescence associated with nodules using box-plots showing $\mathbf{I}$, total lux intensity per nodule and $\mathbf{J}$, mean lux intensity per pixel. All the visible nodules within a plate were analyzed by selecting an area of 50-by-50-pixels around each nodule or nodule cluster. Background subtraction for lux was performed by selecting a similar area of 50-by-50-pixels, where no roots were visible (average of three). Six plates were imaged from two independent trials (three plates/trial), $n=49$ to 53 individual nodules or nodule clusters, from the independent six GInLux-agar plates (Fig. 1). Stars indicate significant differences between nondefoliated and defoliated roots for luminescence $(* \star \star * P<0.0001)$. RLU, relative light units. 

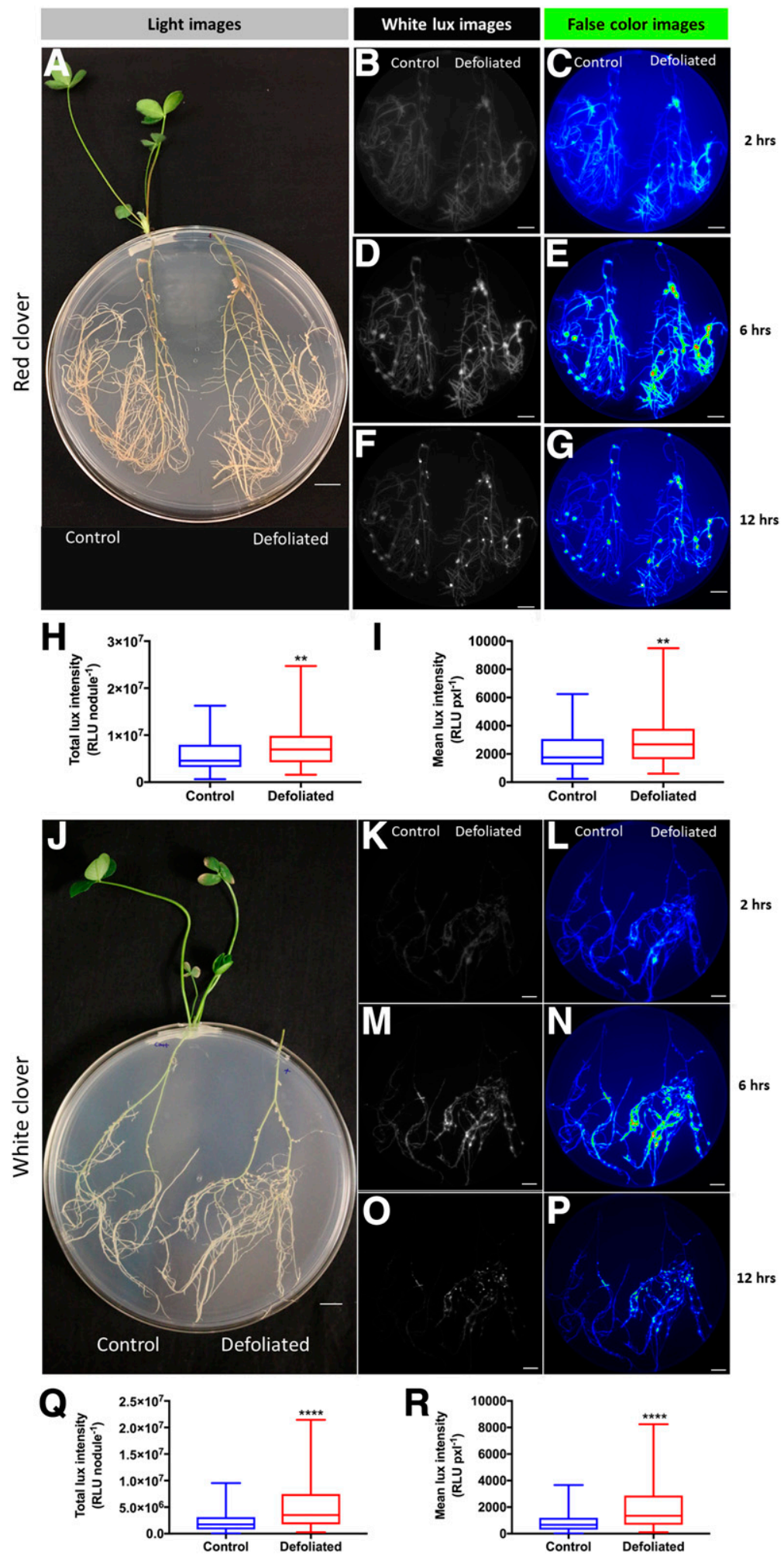

Fig. 2. Imaging and quantification of Gln release from nodulated root systems of $\mathbf{A}$ to $\mathbf{I}$, red clover and $\mathbf{J}$ to $\mathbf{R}$, white clover following defoliation or nondefoliated controls, using the GInLux-agar biosensor assay. A and J, Light image of a root systems of a representative 6-week-old A, red clover plant and $\mathbf{J}$, white clover plant that were defoliated (right) and a noninjured control (left) placed on a GInLux-agar plate. B, D, F, K, M, and O, White lux images and C, E, G, L, N, and P, false-colored lux images after 2, 6, and $12 \mathrm{~h}$ of incubation immediately after defoliation. Bright green-yellowred color areas with halos represent plant tissues showing the greatest Gln release including nodules. Corresponding quantitative analysis of luminescence associated with nodules of red clover $(\mathbf{H}$ to $\mathbf{I})$ and white clover $(\mathbf{Q}$ to $\mathbf{R})$ using box-plots showing total lux intensity per nodule $(\mathbf{H}$ and $\mathbf{Q})$ and mean lux intensity per pixel for red and white clover (I and $\mathbf{R})$, respectively. All the visible nodules within a plate were analyzed by selecting an area of 50-by-50-pixels around each nodule or nodule cluster. Background subtraction for lux was performed by selecting a similar area of 50-by-50-pixels, where no roots were visible (average of three). Six plates were imaged per crop from two independent trials (three plates/trial), $n=66$ to 69 (red clover) and 62 to 73 (white clover) nodules/nodule clusters, from the six completely independent GInLux-agar plates (Fig. 2). Stars indicate significant differences between nondefoliated and defoliated roots for luminescence $\left({ }^{\star *}=P<0.01 ;{ }^{* * *}=P<0.0001\right)$. RLU, relative light units. 
Wen et al. 2007). Indeed, defoliation-induced Gln release from young lateral roots and root tips was also observed here. Nodule $\mathrm{N}$ release was previously suggested, but via multiweek decomposition (Fustec et al. 2010; Thilakarathna et al. 2016a).

The questions that now arise are as follows: What are the causes and implications of defoliation stimulating rapid releases of organic $\mathrm{N}$ ? What is the mechanism underlying direct $\mathrm{N}$ release from nodules?

Rapid defoliation-induced GIn release from legume root systems. Here, defoliation stimulated Gln release into the rhizosphere within only $2 \mathrm{~h}$, which diminished within $12 \mathrm{~h}$, compared with previous results (Brophy and Heichel 1989; Ta et al. 1986) which suggested that $\mathrm{N}$ exudation is slow and extended. GlnLux cells detect only free Gln (Tessaro et al. 2012). This is important, because defoliation reduces carbon supplies to nodules (Gordon et al. 1986), potentially limiting energy-intensive $\mathrm{N}$ fixation and assimilation into Gln (Aranjuelo et al. 2015), thereby reducing the free Gln pool inside nodules. Hence, one interpretation of these findings is that the pattern of rhizosphere lux emissions postdefoliation was stimulated by the rapid release and depletion of the pre-existing, predefoliation pool of free Gln inside root systems. The steady-state level of free Gln is low in roots of amide-exporting legumes (including alfalfa and clovers), yet critical to plant growth, because Gln is rapidly converted/transported into essential $\mathrm{N}$ compounds (Prell and Poole 2006).

If rapid release of free Gln postdefoliation also occurs in soil, it could have different fates based on prior $\mathrm{N}$ exudate studies: reuptake by the regrowing plant (Näsholm et al. 2009), direct $\mathrm{N}$ transfer to nonlegumes (Paynel and Cliquet 2003; Paynel et al. 2008; Jalonen et al. 2009a, b), uptake by rhizosphere microbes (van Kessel et al. 2009) potentially to benefit plant regrowth (Sasse et al. 2018), and leaching into groundwater in natural ecosystems (Aber et al. 2002; Eshleman and Raymond 1998) and agroecosystems (Thilakarathna et al. 2012, 2016b; Wachendorf et al. 2004).

Interestingly, in an earlier study, defoliated soybean showed increased root colonization by arbuscular mycorrhizae fungi (AMF) (Bayne et al. 1984). AMF are efficient in uptaking $\mathrm{N}$ compounds including amino acids (He et al. 2003; Lipson and Näsholm 2001). Furthermore, the common mycorrhizal network interconnecting the roots of legumes and nonlegumes facilitates $\mathrm{N}$ transfer $(\mathrm{He}$ et al. 2003). Therefore, AMF may minimize the free Gln losses postdefoliation, but this conclusion awaits further study. Alternatively, Gln not absorbed by AMF is highly bioavailable and would be desired by rhizosphere microbes (Sasse et al. 2018).

Mechanisms underlying defoliation-induced GIn release directly from nodules. Defoliation triggers diverse physiological and biochemical activities inside nodules including the following: reduced nitrogenase activity (Cralle and Heichel 1981; Denison et al. 1992), reduced glutamine synthetase (Jacobi et al. 1994), increased protease and nitrate reductase along with rapid localized senescence (Vance et al. 1979), decreased $\mathrm{O}_{2}$ permeability (Denison et al. 1992), reduced soluble protein, sugar/starch, leghemoglobin (Denison et al. 1992; Gordon et al. 1986), and cellular disintegration (Gordon et al. 1990). Nitrogen release from nodules can now be added to the list of early defoliation responses. As to the cause, as noted above, since defoliation starves nodules for carbon, it may deplete the energy required for nodule maintenance (e.g., wall integrity) (Aranjuelo et al. 2015) including the energy barrier that prevents diffusion losses from roots and nodules (Ta et al. 1986). It was reported that the sucrose concentration in nodules can be depleted by more than $50 \%$ within the first hour after defoliation (70\% defoliation) compared with the nondefoliated control in white clover (Gordon et al. 1986). Metabolite diffusion occurs only from young roots (due to lack of Casparian strips or suberized endodermis) (Sasse et al. 2018), relevant here since only young plants were imaged. It would also be interesting to explore whether $\mathrm{N}$ exudation is the result of a defoliation-mediated active signaling cascade (e.g., reduced auxin/strigolactones/small RNAs due to lost shoot buds).

Study limitations. There were several study limitations. The GlnLux-agar assay visualizes only free Gln, which constitutes only a fraction of N-containing root exudates (Lesuffleur et al. 2007; Paynel et al. 2001). Plant-to-plant variation was observed for Gln output between GlnLux images, possibly due to variation in nodulation profiles (nodule number/size) between plants. The study environment was artificial, without soil or living microbes including vesicular arbuscular mycorrhiza. Directly extrapolating these findings may be challenging, as the magnitude (and possibly timing) of $\mathrm{N}$ exudation can vary by species/cultivar (Thilakarathna et al. 2016a, 2018).

Future perspectives. Rhizodeposited nitrogen can constitute 4 to $71 \%$ of total plant $\mathrm{N}$, depending on genetic and environmental factors (Fustec et al. 2010; Wichern et al. 2008), and their interplay may be complex. Direct imaging of $\mathrm{N}$ exudation creates new opportunities to screen for elicitors of $\mathrm{N}$ release from nodules and roots including rhizosphere microbes. Interestingly, photon emission was also noticed from GlnLux-agar exposed to roots from nondefoliated plants (Figs. 1 and 2), possibly due to steady-state Gln efflux. Several mechanisms have been proposed to mediate root exudation (diffusion, active transport, and exocytosis) (Oburger and Jones 2018) but the $\mathrm{N}$ export machinery remains largely unknown with no authentic root-to-rhizosphere export transporters identified (Besnard et al. 2016; Moe 2013; Sasse et al. 2018; Yu et al. 2015). Direct imaging may facilitate screens for mutants that may be informative.

\section{ACKNOWLEDGMENTS}

We thank A. Shrestha (University of Guelph) for her significant experimental assistance; J. Frugoli (Clemson University) and M. Janczarek (Maria Curie-Skłodowska University in Lublin) for providing rhizobia strains; Y. Papadopoulos (Agriculture and AgriFood Canada) for providing seeds; and L. Smith (University of Guelph) for preparing graphic illustrations.

\section{LITERATURE CITED}

Aber, J. D., Ollinger, S. V., Driscoll, C. T., Likens, G. E., Holmes, R. T., Freuder, R. J., et al. 2002. Inorganic nitrogen losses from a forested ecosystem in response to physical, chemical, biotic, and climatic perturbations. Ecosystems (N.Y.) 5:648-658.

Aranjuelo, I., Molero, G., Erice, G., Aldasoro, J., Arrese-igor, C., and Nogués, S. 2015. Effect of shoot removal on remobilization of carbon and nitrogen during regrowth of nitrogen-fixing alfalfa. Physiol. Plant. 153:91-104.

Ayres, E., Dromph, K. M., Cook, R., Ostle, N., and Bardgett, R. D. 2007. The influence of below-ground herbivory and defoliation of a legume on nitrogen transfer to neighbouring plants. Funct. Ecol. 21:256-263.

Ayres, E., Heath, J., Possell, M., Black, H. I. J., Kerstiens, G., and Bardgett, R. D. 2004. Tree physiological responses to above-ground herbivory directly modify below-ground processes of soil carbon and nitrogen cycling. Ecol. Lett. 7:469-479.

Badri, D. V., and Vivanco, J. M. 2009. Regulation and function of root exudates. Plant Cell Environ. 32:666-681.

Bayne, H. G., Brown, M. S., and Bethlenfalvay, G. J. 1984. Defoliation effects on mycorrhizal colonization, nitrogen fixation and photosynthesis in the Glycine-Glomus-Rhizobium symbiosis. Physiol. Plant. 62:576-580.

Bazot, S., Mikola, J., Nguyen, C., and Robin, C. 2005. Defoliation-induced changes in carbon allocation and root soluble carbon concentration in fieldgrown Lolium perenne plants: Do they affect carbon availability, microbes and animal trophic groups in soil? Funct. Ecol. 19:886-896. 
Besnard, J., Pratelli, R., Zhao, C., Sonawala, U., Collakova, E., Pilot, G., et al. 2016. UMAMIT14 is an amino acid exporter involved in phloem unloading in Arabidopsis roots. J. Exp. Bot. 67:6385-6397.

Brophy, L. S., and Heichel, G. H. 1989. Nitrogen release from roots of alfalfa and soybean grown in sand culture. Plant Soil 116:77-84.

Carrillo, Y., Jordan, C. F., Jacobsen, K. L., Mitchell, K. G., and Raber, P. 2011. Shoot pruning of a hedgerow perennial legume alters the availability and temporal dynamics of root-derived nitrogen in a subtropical setting. Plant Soil 345:59-68

Corre, N., Bouchart, V., Ourry, A., and Boucaud, J. 1996. Mobilization of nitrogen reserves during regrowth of defoliated Trifolium repens $\mathrm{L}$. and identification of potential vegetative storage proteins. J. Exp. Bot. 47: 1111-1118.

Coskun, D., Britto, D. T., Shi, W., and Kronzucker, H. J. 2017. How plant root exudates shape the nitrogen cycle. Trends Plant Sci. 22:661-673.

Cralle, H. T., and Heichel, G. H. 1981. Nitrogen fixation and vegetative regrowth of alfalfa and birdsfoot trefoil after successive harvests or floral debudding. Plant Physiol. 67:898-905.

Denison, R. F., Hunt, S., and Layzell, D. B. 1992. Nitrogenase activity, nodule respiration, and $\mathrm{O}_{2}$ permeability following detopping of alfalfa and birdsfoot trefoil. Plant Physiol. 98:894-900.

Eshleman, K. N., and Raymond, P. M. 1998. Temporal patterns of nitrogen leakage from mid-Appalachian defoliation fluxes from mid-Appalachian forested watersheds: Role of insect defoliation. Water Resour. Res. 34: 2005-2016.

Fustec, J., Lesuffleur, F., Mahieu, S., and Cliquet, J. B. 2010. Nitrogen rhizodeposition of legumes. A review. Agron. Sustain. Dev. 30:57-66.

Gordon, A. J., Kessler, W., and Minchin, F. R. 1990. Defoliation-induced stress in nodules of white clover. J. Exp. Bot. 41:1245-1253.

Gordon, A. J., Ryle, G. J. A., Mitchell, D. F., Lowry, K. H., and Powell, C. E. 1986. The effect of defoliation on carbohydrate, protein and leghaemoglobin content of white clover nodules. Ann. Bot. 58:141-154.

Goron, T. L., and Raizada, M. N. 2016. Biosensor-based spatial and developmental mapping of maize leaf glutamine at vein-level resolution in response to different nitrogen rates and uptake/assimilation durations. BMC Plant Biol. 16:230.

Hamilton, E. W., Frank, D. A., Hinchey, P. M., and Murray, T. R. 2008 Defoliation induces root exudation and triggers positive rhizospheric feedbacks in a temperate grassland. Soil Biol. Biochem. 40:2865-2873.

He, X. H., Critchley, C., and Bledsoe, C. 2003. Nitrogen transfer within and between plants through common mycorrhizal networks (CMNs). Crit. Rev. Plant Sci. 22:531-567.

Høgh-Jensen, H., and Schjoerring, J. K. 1994. Measurement of biological dinitrogen fixation in grassland: Comparison of the enriched ${ }^{15} \mathrm{~N}$ dilution and the natural ${ }^{15} \mathrm{~N}$ abundance methods at different nitrogen application rates and defoliation frequencies. Plant Soil 166:153-163.

Holland, J. N., Cheng, W., and Crossley, D. A. 1996. Herbivore-induced changes in plant carbon allocation: Assessment of below-ground $\mathrm{C}$ fluxes using carbon-14. Oecologia 107:87-94.

Jacobi, A., Katinakis, P., and Werner, D. 1994. Artificially induced senescence of soybean root nodules affects different polypeptides and nodulins in the symbiosome membrane compared to physiological ageing. J. Plant Physiol. 144:533-540.

Jalonen, R., Nygren, P., and Sierra, J. 2009a. Root exudates of a legume tree as a nitrogen source for a tropical fodder grass. Nutr. Cycl. Agroecosyst. 85: 203-213.

Jalonen, R., Nygren, P., and Sierra, J. 2009b. Transfer of nitrogen from a tropical legume tree to an associated fodder grass via root exudation and common mycelial networks. Plant Cell Environ. 32:1366-1376.

Janczarek, M., Jaroszuk-Ściseł, J., and Skorupska, A. 2009. Multiple copies of $\operatorname{ros} R$ and pssA genes enhance exopolysaccharide production, symbiotic competitiveness and clover nodulation in Rhizobium leguminosarum bv. trifolii. Antonie van Leeuwenhoek 96:471-486.

Kassaw, T., Jr., Bridges, W., and Frugoli, J. 2015. Multiple autoregulation of nodulation (AON) signals identified through split root analysis of Medicago truncatula sunn and rdn1 mutants. Plants 4:209-224.

Lesuffleur, F., and Cliquet, J. B. 2010. Characterisation of root amino acid exudation in white clover (Trifolium repens L.). Plant Soil 333:191-201.

Lesuffleur, F., Paynel, F., Bataillé, M. P., Le Deunff, E., and Cliquet, J. B. 2007. Root amino acid exudation: Measurement of high efflux rates of glycine and serine from six different plant species. Plant Soil 294:235-246.

Lipson, D., and Näsholm, T. 2001. The unexpected versatility of plants: Organic nitrogen use and availability in terrestrial ecosystems. Oecologia 128: 305-316.
Moe, L. A. 2013. Amino acids in the rhizosphere: From plants to microbes. Am. J. Bot. 100:1692-1705.

Murray, P., Ostle, N., Kenny, C., and Grant, H. 2004. Effect of defoliation on patterns of carbon exudation from Agrostis capillaris. J. Plant Nutr. Soil Sci. 167:487-493.

Näsholm, T., Kielland, K., and Ganeteg, U. 2009. Uptake of organic nitrogen by plants. New Phytol. 182:31-48.

Oburger, E., and Jones, D. L. 2018. Sampling root exudates-Mission impossible? Rhizosphere 6:116-133.

Ofosu-Budu, K. G., Saneoka, H., and Fujita, K. 1995a. Analysis of factors controlling dinitrogen fixation and nitrogen release in soybean using pod removal, stem girdling, and defoliation. Soil Sci. Plant Nutr. 41:407-416.

Ofosu-Budu, K. G., Saneoka, H., and Fujita, K. 1995b. Factors controlling the release of nitrogenous compounds from roots of soybean. Soil Sci. Plant Nutr. 41:625-633.

Paynel, F., and Cliquet, J. B. 2003. N transfer from white clover to perennial ryegrass, via exudation of nitrogenous compounds. Agronomie 23:503-510.

Paynel, F., Lesuffleur, F., Bigot, J., Diquélou, S., and Cliquet, J.-B. 2008. A study of ${ }^{15} \mathrm{~N}$ transfer between legumes and grasses. Agron. Sustain. Dev. 28: 281-290.

Paynel, F., Murray, P. J., and Bernard Cliquet, J. 2001. Root exudates: A pathway for short-term $\mathrm{N}$ transfer from clover and ryegrass. Plant Soil 229: 235-243.

Prell, J., and Poole, P. 2006. Metabolic changes of rhizobia in legume nodules. Trends Microbiol. 14:161-168.

Saj, S., Mikola, J., and Ekelund, F. 2008. Legume defoliation affects rhizosphere decomposers, but not the uptake of organic matter $\mathrm{N}$ by a neighbouring grass. Plant Soil 311:141-149.

Sasse, J., Martinoia, E., and Northen, T. 2018. Feed your friends: Do plant exudates shape the root microbiome? Trends Plant Sci. 23:25-41.

Ta, T. C., Macdowall, F. D. H., and Faris, M. A. 1986. Excretion of nitrogen assimilated from $\mathrm{N}_{2}$ fixed by nodulated roots of alfalfa (Medicago sativa). Can. J. Plant Sci. 64:2063-2067.

Tarui, A., Matsumura, A., Asakura, S., Yamawaki, K., Hattori, R., and Daimon, H. 2013. Enhancement of nitrogen uptake in oat by cutting hairy vetch grown as an associated crop. Plant Root 7:83-91.

Tegeder, M. 2014. Transporters involved in source to sink partitioning of amino acids and ureides: Opportunities for crop improvement. J. Exp. Bot. 65: 1865-1878.

Tessaro, M. J., Soliman, S. S. M., and Raizada, M. N. 2012. Bacterial whole-cell biosensor for glutamine with applications for quantifying and visualizing glutamine in plants. Appl. Environ. Microbiol. 78:604-606.

Thilakarathna, M. S., McElroy, M. S., Chapagain, T., Papadopoulos, Y. A., and Raizada, M. N. 2016a. Belowground nitrogen transfer from legumes to nonlegumes under managed herbaceous cropping systems. A review. Agron. Sustain. Dev. 36:58

Thilakarathna, M. S., Moroz, N., and Raizada, M. N. 2017. A biosensor-based leaf punch assay for glutamine correlates to symbiotic nitrogen fixation measurements in legumes to permit rapid screening of rhizobia inoculants under controlled conditions. Front. Plant Sci. 8:1714.

Thilakarathna, M. S., Papadopoulos, Y. A., Grimmett, M., Fillmore, S. A. E., Crouse, M., and Prithiviraj, B. 2018. Red clover varieties show nitrogen fixing advantage during the early stages of seedling development. Can. J. Plant Sci. 98:517-526.

Thilakarathna, M. S., Papadopoulos, Y. A., Rodd, A. V., Grimmett, M., Fillmore, S. A. E., Crouse, M., et al. 2016b. Nitrogen fixation and transfer of red clover genotypes under legume-grass forage based production systems. Nutr. Cycl. Agroecosyst. 106:233-247.

Thilakarathna, M. S., and Raizada, M. N. 2018. Visualizing glutamine accumulation in root systems involved in the legume-rhizobia symbiosis by placement on agar embedded with companion biosensor cells. Phytobiomes J. 2:117-128.

Thilakarathna, M. S., Serran, S., Lauzon, J., Janovicek, K., and Deen, B. 2015. Management of manure nitrogen using cover crops. Agron. J. 107:1595-1607.

Thilakarathna, R. M. M. S., Papadopoulos, Y. A., Rodd, A. V., Gunawardena, A. N., Fillmore, S. A. E., and Prithiviraj, B. 2012. Characterizing nitrogen transfer from red clover populations to companion bluegrass under field conditions. Can. J. Plant Sci. 92:1163-1173.

Udvardi, M., and Poole, P. S. 2013. Transport and metabolism in legumerhizobia symbioses. Annu. Rev. Plant Biol. 64:781-805.

Unkovich, M., Herridge, D., Peoples, M., Cadisch, G., Boddey, B., Giller, K., et al. 2008. Measuring plant-associated nitrogen fixation in agricultural systems. Australian Centre for International Agricultural Research. Monograph No. 136. 
van Kessel, C., Clough, T., and van Groenigen, J. W. 2009. Dissolved organic nitrogen: An overlooked pathway of nitrogen loss from agricultural systems? J. Environ. Qual. 38:393-401.

Vance, C. P., Heichel, G. H., Barnes, D. K., Bryan, J. W., and Johnson, L. E. 1979. Nitrogen fixation, nodule development, and vegetative regrowth of alfalfa (Medicago sativa L.) following harvest. Plant Physiol. 64:1-8.

Wachendorf, M., Buchter, M., Trott, H., and Taube, F. 2004. Performance and environmental effects of forage production on sandy soils. II. Impact of defoliation system and nitrogen input on nitrate leaching losses. Grass Forage Sci. 59:56-68.
Wen, F., VanEtten, H. D., Tsaprailis, G., and Hawes, M. C. 2007. Extracellular proteins in pea root tip and border cell exudates. Plant Physiol. 143:773783.

Wichern, F., Eberhardt, E., Mayer, J., Joergensen, R. G., and Müller, T. 2008. Nitrogen rhizodeposition in agricultural crops: Methods, estimates and future prospects. Soil Biol. Biochem. 40:30-48.

Yu, S., Pratelli, R., Denbow, C., and Pilot, G. 2015. Suppressor mutations in the Glutamine Dumper1 protein dissociate disturbance in amino acid transport from other characteristics of the Gdu1D phenotype. Front. Plant Sci. 6:593. 